\title{
Analysis on Ecological Environment Change of Kalajun-Kurdening World Natural Heritage Site from 2006 to 2019
}

\author{
Hui Ye* \\ Xinjiang University of Finance and Economics, Urumqi 830012, China
}

Received: 11 November 2020

Accepted: 8 April 2021

\begin{abstract}
Scientific evaluation and dynamic monitoring of regional ecological environment have important reference value for the establishment and implementation of regional ecological environment protection and restoration measures. Spatial principle component analysis was used to assess the present situation and the temporal and spatial variation characteristics of ecological environment of Kalajun-Kurdening natural heritage site by calculating the remote sensing ecological index (RSEI) and analyzing the landscape pattern. Three results are presented: (1) During 2006-2019, the mean values of the greenness indicator showed an increasing trend, with an increase of $10.58 \%$, which proves that the vegetation coverage in Kalajun-Kurdening shows an increasing trend year by year. The other three indicators of dryness, moisture, and heat decreased by $134.51 \%, 14.66 \%$, and $3.45 \%$ respectively. The change of greenness and dryness has a stronger positive effect on the ecological environment quality, while the negative effect of heat on the ecological environment quality is reduced. (2) During the 14 years, the regional RSEI of $1104.23 \mathrm{~km}^{2}$ remained unchanged, accounting for $54.32 \%$ of the total area. The area with a descending RSEI is $547.23 \mathrm{~km}^{2}$, accounting for $26.92 \%$ of the total area, $84.52 \%$ of which had a drop of one level. The area with the rising RSEI is $381.31 \mathrm{~km}^{2}$, accounting for $18.75 \%$ of the total area, $90.56 \%$ of which has a rising by one level. (3) Landscape indexes of the different grade of RSEI in Kalajun-Kurdening showed that the landscape fragmentation was small, the structural complexity was reduced, and the landscape patches were regularized, artificial, and centralized; different types of RSEI had obvious agglomeration; and the cohesion between patches was relatively good. Overall, the ecological environment quality of the Kalajun-Kurdening world natural heritage site showed an upward trend from 2006 to 2019 without large-scale deterioration of, maintaining in good condition.
\end{abstract}

Keywords: ecological environment, remote sensing, landscape pattern, spatial-temporal variation

*e-mail:65175799@qq.com 


\section{Introduction}

A natural heritage is a natural zone of Outstanding Universal Value with natural landforms, geological or geographical structures, natural places of interest and clearly defined habitats of endangered animals and plants [1]. The study on the temporal and spatial pattern and evolution of the ecological environment of natural heritage sites is conducive to a comprehensive understanding of the overall condition and spatial distribution of the ecological environment [2], and has important practical significance for targeted ecological environment construction and protection [3]. For example, Allan J.R. et al. analyzed global natural heritage sites threatened by human footprint and forest loss [4]; Shi Hui et al. analyzed the landscape ecological security and ecological environment vulnerability of Tianchi and Tomur in Tianshan, Xinjiang, respectively, and discussed the driving mechanism of the pattern evolution of Tianchi scenic area [2], and divided the Tomur region according to the vulnerability level [5]. However, there are few studies on natural heritage sites through the integrated monitoring of remote sensing and landscape pattern analysis.

Ecological environment is the material basis for human survival and development [6]. Since the $20^{\text {th }}$ century, climate warming has been increasingly intensified, and the global climate and environment have undergone great changes [7]. The loss of species diversity, frequent occurrence of extreme weather events, intensification of desertification and melting of polar glaciers are strong feedbacks to the changes of ecological system, which greatly threaten the survival of human beings and the sustainable development of social economy [8]. Excessive and disordered exploitation and utilization of ecological resources has led to a series of ecological and environmental problems such as ecosystem degradation, energy shortage and land desertification [9]. As the most intuitive manifestation of human development and utilization of natural environment, land use/cover and other surface elements are in constant change and dynamic balance, driving the change of global ecological process and forming the regional spatial differentiation of surface landscape [10].

Vulnerable ecological environment is the sensitive response and self-recovery ability of an ecosystem in a specific space and time scale relative to external disturbance, and also an inherent internal natural attribute of the system itself [11]. As one of the core hotspots in global geography, ecology and environmental science, it is the result of the interaction of natural and human factors, and can objectively describe the degree of regional ecological environment quality [12]. Scientific evaluation and dynamic monitoring of regional ecological environment have important reference value for the establishment and implementation of regional ecological environment protection and restoration measures [13]. Therefore, the research of temporal and spatial difference of ecological environment is carried out to deeply analyze the formation reasons and driving mechanism of ecosystem vulnerable problems, so as to provide decision-making basis and technical support for guiding the protection of ecological areas and restoration and governance of ecological environment [14].

Researches on ecological environment assessment originated in 1905 [15]. Since the 1980s, scholars have conducted in-depth studies on the systematic assessment of ecological vulnerability and the influencing factors of system changes, and applied landscape ecology, RS/ GIS and other spatial analysis methods to the ecological environment assessment [16]. At present, remote sensing technology can quickly and quantitatively evaluate the changes of ecological environment [17]. Remote sensing technology has been widely used in ecological environment basins due to its advantages of rapid and real-time, etc., and has become an important means of ecological environment assessment [18].

In the aspect of index system research, it can be divided into single index and comprehensive index:(1) According to a single index, the different functions of an ecosystem are interrelated and constitute the overall function of the system. A single index, such as vegetation index represented by NDVI, temperature inversion index represented by LST and land use type change index, can only reflect a certain function of the ecosystem unilaterally and separate the overall function [15]. For example, Badreldin et al. used disturbance index and soil adjustment index to dynamically monitor desertification in the Sinai Peninsula region of Egypt [19]; Franke et al. studied the dynamic process of grassland degradation by using normalized difference vegetation index [20]. The advantages of single index are easy to understand and easy to calculate, but it is difficult to grasp the systematicness of ecological environment. (2) Comprehensive ecological environment index can contain more ecological environment characteristics related to research objectives. The ecological environment evaluation model composed entirely of remote sensing data is characterized by timeliness and rapidity [21]. However, the application of ecological index (EI) containing other types of data is limited to some extent due to the difficulty in obtaining monitoring data and statistical data. The monitoring of ecological environment is mostly based on statistical data, monitoring data or remote sensing data [22]. Comprehensive index method is adopted to conduct qualitative or quantitative analysis around a certain period of time in the research area to describe the temporal and spatial changes of ecological environment [23]. When scholars use remote sensing technology to monitor the ecological environment, most of them are still based on a single evaluation index, and the indexes and weights need to be adjusted artificially in studies in different regions. And multi-index remote sensing ecological index (Remote Sensing Ecology Index, RSEI), based on remote sensing information, can integrate the four indexes of greenness, humidity, 
dryness and heat. There is no need to choose the weight of ecological index, and the calculated results are objective and stable. At present, some scholars have made ecological change analysis by using remote sensing ecological index in some cities. The results show that RSEI has a good effect on the evaluation of regional ecological environment quality, and can comprehensively reflect the change characteristics of regional ecological environment quality [24].

Due to the highly comprehensive and regional characteristics of the landscape itself, some scholars, from the perspective of landscape ecology, adopt the spatial distribution and gradient change characteristics of landscape information to establish evaluation models, so as to realize the quantitative and spatial evaluation of ecological environment vulnerability [25]. However, because of the differences in the evaluation objects, the selection of indicators has different focuses, which affects their unified academic cognition.

In recent years, dynamic assessment and analysis of ecological environment combined with landscape pattern index has become a research focus and application field of landscape ecology. Landscape, as the living environment of human beings and various creatures, shows obvious regional characteristics [26]. Research shows that there is an internal correlation between landscape pattern information and ecological environment vulnerability, which provides new research methods and ideas for ecological vulnerability assessment. The landscape pattern shows the spatial relationship and gradient change characteristics of different ecosystem or landscape units [27].

Most scholars construct the landscape ecological vulnerability framework from the landscape pattern level, but there are few studies on both landscape pattern and RSEI. Therefore, it is particularly important to study the temporal and spatial changes of regional landscape ecological vulnerability from the perspective of RSEI and landscape pattern as a whole. In terms of the influencing factors, the current researches on the influencing factors of landscape ecological vulnerability are mostly qualitative and relatively few quantitative studies, and the multi-scale analysis of the influencing factors is even more lacking. In order to better reveal the influencing factors and differences of ecological environment at different scales, it is necessary to study the spatio-temporal evolution and multi-scale driving factors of landscape ecological vulnerability in diverse geographical regions.

\section{Materials and Methods}

\section{Study Area}

The Kalajun-Kurdening world natrual heritage site is located in the Ili River Valley in the central part of the Tianshan Mountains in Xinjiang, with a core area of 1,138. $18 \mathrm{~km}^{2}$, and a buffer area 893. $46 \mathrm{~km}^{2}$ (Fig. 1). On June 21, 2013, Xinjiang Tianshan was ratified as a world natural heritage site by the United Nations Educational Scientific and Cultural Organization (UNESCO), making it the $47^{\text {th }}$ world heritage site in China. The Bayanbulak, Bogda, Kalajun-Kurdening, and Tomur components constitute the Xinjiang Tianshan World Heritage Site. The Kalajun-Kurdening is the region with the richest biodiversity in Tianshan Mountain, Xinjiang, and is the most typical representative of Tianshan coniferous forest and Tianshan mountain grassland meadow in "Central Asia Mountain Grassland and Forest Land Ecological Zone" of Ecoregions 111 of Global 200. As the best habitat and origin of the world's snow Ridge spruce and the central Asian wild fruit forest, it provides a valuable habitat environment for many tertiary relic species and has been named as the "natural gene pool" of wildlife species in the hinterland of Eurasia. It has the biological landscape resources with the highest aesthetic value in Tianshan mountain. The biodiversity, geomorphic diversity and climate diversity have created the landscape aesthetic diversity, making it the most prominent representative of the integrated natural landscape beauty of temperate arid mountainous areas [14].
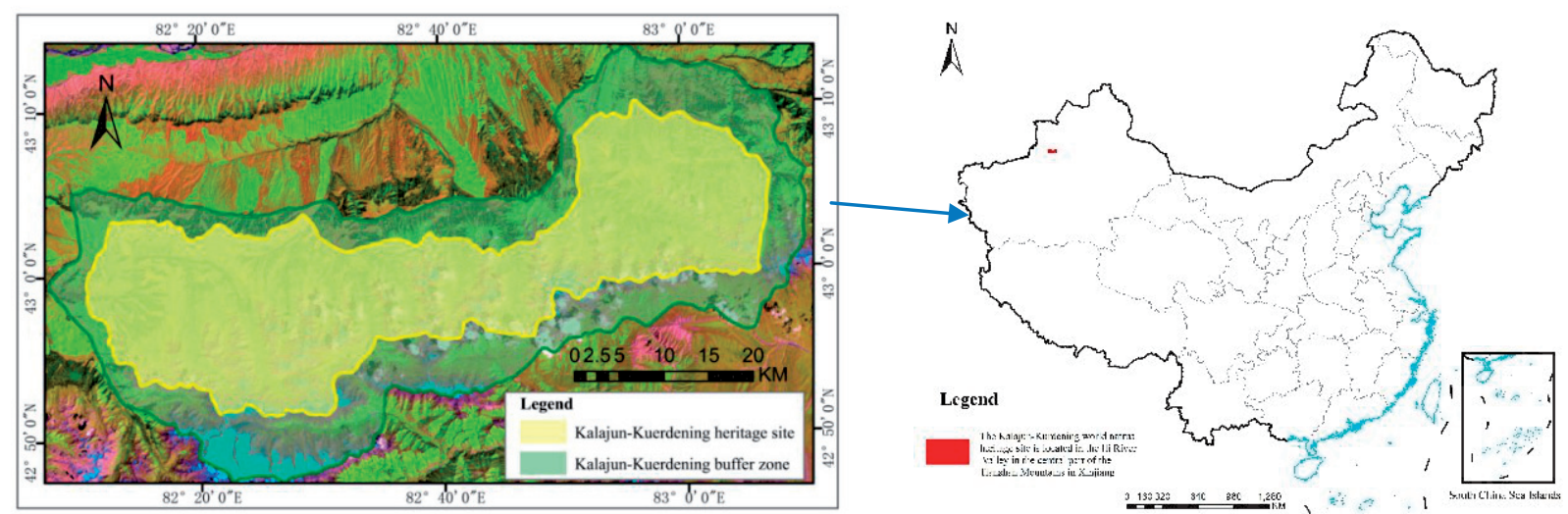

Fig. 1. Location of the study area. Map Content Approval Number: GS(2019)1822. 


\section{Data Sources and Data Processing}

Landsat series images were used for the data in the research, which were successively Landsat $5 \mathrm{TM}$ data on July 17, 2006 and Landsat 8 OLI data on July 18, 2019 with orbit number 146/030 and a spatial resolution of $30 \mathrm{~m}$, downloaded from the United States Geological Survey (https://www.usgs.gov/). The imaging time was relatively close, and the data cloud cover was relatively small. Using ENVI 5.1 software, each image in each period is radiatively calibrated, and the pixel value of each image is converted into the reflectivity of the sensor. The FLAASH absolute atmospheric correction was used to correct each image to reduce the difference of the image generated in different periods of light, atmosphere and other conditions, and the images of different periods are seamlessly embedded, covering all areas of the research area. Finally, all images were cut by the boundary of the study area, and the root mean square error of the registration should be less than 0.5 pixels, which is satisfied the requirement of data accuracy in this study.

\section{Research Methods}

Remote sensing ecological index (RSEI) selects four important indicators inseparable with human living environment - greenness, moisture, heat and dryness to objectively and comprehensively evaluate the ecological environment. The remote sensing ecological index (RSEI) was proposed by Xu Hanqiu [24]. It was used to calculate the ecological index, by extracting a number of indicators that can reflect the ecological status, including vegetation index, moisture component, surface temperature, building index and bare soil index, and synthesizes them. Dimensionality reduction is achieved through spatial principal component analysis (SPCA) [28]. Principal component containing multiple index information is adopted as an indicator to represent the ecological status. The four indicators can be extracted by remote sensing image information. Vegetation indicator (NDVI) represents greenness, land surface moisture component (LSM) is used to represent moisture, surface temperature (LST) represents heat index, and normalized difference imperviousness and soil index (NDISI) represents dryness index.

\section{Index Calculation of RSEI}

\section{- Greenness (NDVI)}

Vegetation is a very important factor to reflect the regional ecological quality [29]. Normalized difference vegetation index (NDVI) is the most widely used vegetation index, which can reflect the relationship between plant biomass, leaf area index and vegetation coverage [30]. Therefore, NDVI can be selected as the green index in this paper, and its formula is:

$$
N D V I=\left(\rho_{N I R}-\rho_{R}\right) /\left(\rho_{N I R}+\rho_{R}\right)
$$

...where the $\rho_{R}$ and $\rho_{N I R}$ are the reflectance data of infrared and near-infrared bands of TM 5 and OLI 8 respectively.

- Moisture (LSM)

The brightness, greenness and moisture components of tasseled cap are closely related to the ecological quality [31]. Among them, the moisture component can reflect the soil and vegetation and the humidity condition in the study area [32]. Therefore, land surface moisture (LSM) is used to represent humidity index in this paper. Based on Landsat TM and Landsat OLI reflectivity image data, the formula is:

$$
L S M=C_{1} \rho_{B}+C_{2} \rho_{G}+C_{3} \rho_{R}+C_{4} \rho_{\text {NIR }}+C_{5} \rho_{\text {SWIR1 }}+C_{6} \rho_{\text {SWIR } 2}
$$

...where the $\rho_{B}, \rho_{G}, \rho_{R}, \rho_{\text {NIR }}, \rho_{\text {SWIRI }}$ and $\rho_{\text {SWIR } 2}$ are the reflection rate data of TM and OLI's blue, green, red, near-infrared, short-wave infrared 1 and short-wave infrared 2 bands respectively. $C_{1}, C_{2}, C_{3}, C_{4}, C_{5}$ and $C_{6}$ are the coefficients for calculating humidity, and values in TM image are: $C_{1}=0.0315, C_{2}=0.2021$, $C_{3}=0.3102, C_{4}=0.1594, C_{5}=-0.6806, C_{6}=-0.6109$; Values in OLI image are respectively: $C_{1}=0.1511, C_{2}=0.1973$, $C_{3}=0.3283, C_{4}=0.3407, C_{5}=-0.7117, C_{6}=-0.4559$.

- Heat (LST)

Heat index is expressed by land surface temperature, which is closely related to vegetation and water resources [33]. All satellite-based studies of heat island have verified a close relationship between the satellite-derived surface temperature and land surface temperature. The surface temperature is obtained through the surface specific emissivity correction. The formula is as follows:

$$
\begin{gathered}
L=\text { gain } \times D N+\text { bias } \\
T_{b}=K_{2} / \operatorname{In}\left(K_{1} / L+1\right) \\
L S T=T_{b}\left[1+\left(\lambda T_{b} / \rho\right) \operatorname{In} \varepsilon\right]
\end{gathered}
$$

...where the $\mathrm{L}$ is the at-satellite spectral radiance values of the thermal bands, Band 6 of Landsat TM and Band 10 of Landsat OLI; gain and bias is the gain value and offset value of the corresponding band, and both of the values can be queried from the header file of corresponding image. $T_{b}$ is the at-satellite brightness temperature. $K_{1}$ and $K_{2}$ are the band-specific thermal conversion constants of thermal bands, at Band 6 of Landsat TM, $K_{1}=607.76 \mathrm{~W} /\left(\mathrm{m}^{2} \cdot \mathrm{sr} \cdot \mu \mathrm{m}\right), K_{2}=1260.56 \mathrm{~K}$; at Band 10 of Landsat OLI, $K_{1}=774.89 \mathrm{~W} /\left(\mathrm{m}^{2} \cdot \mathrm{sr} \cdot \mu \mathrm{m}\right)$, $K_{2}=1321.08 \mathrm{~K} \cdot \lambda$ is the wavelength of the thermal infrared band; $\rho=1.4380^{*} 104 \mu \mathrm{m} ; \varepsilon$ is the surface specific emissivity.

\section{- Dryness (NDISI)}

The Impervious Built-up Index (IBI) has been commonly used to map built-up lands accurately [34]. In addition to the built-up lands, patches of bare land 
or sparsely vegetated ground occurred in the deforested or abandoned locations across the study area. For this reason, Soil Index (SI) was also employed to represent these bare areas [35]. Normalized Difference Imperviousness and Soil Index (NDISI) can effectively distinguish impervious and soil features without covering water before processing impervious surface information [36]. The final dryness indicator is made up of the Built-up Index (IBI) and bare Soil Index (SI) synthesis, denoted as NDISI:

$$
\begin{gathered}
I B I=\left\{\begin{array}{l}
2 \rho_{\text {SWIR1 }} /\left(\rho_{\text {SWIR } 1}+\rho_{\text {NIR }}\right)- \\
{\left[\rho_{\text {NIR }} /\left(\rho_{\text {NIR }}+\rho_{R}\right)+\rho_{G} /\left(\rho_{G}+\rho_{\text {SWIR } 1}\right)\right]}
\end{array}\right\}, \\
\left\{\begin{array}{l}
2 \rho_{\text {SWIR1 }} /\left(\rho_{\text {SWIR1 }}+\rho_{\text {NIR }}\right)+ \\
{\left[\rho_{\text {NIR }} /\left(\rho_{\text {NIR }}+\rho_{R}\right)+\rho_{G} /\left(\rho_{G}+\rho_{\text {SWIR1 }}\right)\right.}
\end{array}\right. \\
\text { SI }=\left[\left(\rho_{\text {SWIR } 1}+\rho_{R}\right)-\left(\rho_{B}+\rho_{\text {NIR }}\right) /\right. \\
\left.\left(\rho_{\text {SWIR }}+\rho_{R}\right)+\left(\rho_{B}+\rho_{\text {NIR }}\right)\right] \\
\text { NDISI }=(I B I+S I) / 2
\end{gathered}
$$

...where the $\rho_{B}, \rho_{G}, \rho_{R}, \rho_{\text {NIR }}$ and $\rho_{\text {SWIRI }}$ are the planetary reflectance of blue, green, red, near-infrared and midinfrared band of the Landsat 5 TM image and Landsat 8 OLI image respectively.

\section{Standardization of Evaluation Indicators}

Each evaluation index has different properties and dimensions, so it is impossible to directly evaluate ecological environment. Therefore, it is necessary to standardize each evaluation index in order to solve the contradiction between indexes that cannot be directly compared [37]. The four indicators selected in this paper can be divided into positive indicators and negative indicators according to their contribution to ecological environment equality. The positive indicators include greenness and moisture; the negative indicators include dryness and heat [38]. For indicator standardization, range standardization method is adopted, and its formula is:

$$
\text { Positive indicators: } \quad S I_{i}=\frac{I_{i}-I_{\min }}{I_{\max }-I_{\min }} \times 10
$$

Negative indicators: $S I_{i}=\frac{I_{\max }-I_{i}}{I_{\max }-I_{\min }} \times 10$

...where $S I_{i}$ represents the standardized value of indicator $I$, whose range is $0-10 ; I_{i}$ is the actual value of indicator; $I_{\max }$ is the maximum value of indicator $I$; Imin is the minimum value of the indicator $I$.

\section{Synthetic Evaluation Model of RSEI}

Spatial principal component analysis (SPCA) is to transform the relevant multivariate spatial data into a few irrelevant comprehensive indicators by rotating the spatial coordinate axes of the characteristic spectrum, so as to retain the information reflected by many variables to the maximum extent with fewer comprehensive indicators. SPCA does not need to determine the weight of each index artificially, which can avoid the deviation of the final result caused by human factors [39]. In this paper, on the software platform of ENVI 5.1, SPCA is carried out for the four evaluation indicators of standardized greenness, moisture, dryness and heat in the evaluation index system to calculate the RSEI. Its calculation formula is:

$$
R S E I=r_{1} P C_{1}+r_{2} P C_{2}+r_{3} P C_{3}+\ldots+r_{i} P C_{i}
$$

...where $i$ is the quantity of principal component (PC) that remained and $r_{i}$ is the contribution ratio of $P C_{i}$.

The contribution ratio ri is calculated as follows:

$$
r_{i}=p_{i /} \sum_{i=1}^{n} p_{i}
$$

...where $\rho_{i}$ represents the contribution ratio of principal component $\rho_{i}$, and $\mathrm{n}$ is the significant number of principal components that remain.

According to the principle of SPCA, the inversion model of RSEI in the study area is obtained from Table 1:

$$
\begin{aligned}
& R S E I_{2006}=0.6034 \times P C_{1}+0.2895 \times P C_{2}+0.0577 \times P C_{3} \\
& R S E I_{2019}=0.6150 \times P C_{1}+0.2184 \times P C_{2}+0.1073 \times P C_{3}
\end{aligned}
$$

Table 1. The results of spatial principal component analysis.

\begin{tabular}{|c|c|c|c|c|}
\hline \multirow{2}{*}{ Principle component } & \multicolumn{2}{|c|}{ Percent of Eigenvalues/\% } & \multicolumn{2}{c|}{ Accumulative of Eigenvalues/\% } \\
\cline { 2 - 5 } & 2006 & 2019 & 2006 & 2019 \\
\hline 1 & 60.34 & 61.50 & 60.34 & 61.50 \\
\hline 2 & 28.95 & 21.84 & 89.29 & 83.35 \\
\hline 3 & 5.77 & 10.73 & 95.06 & 94.08 \\
\hline 4 & 2.93 & 1.91 & 100.00 & 100.00 \\
\hline
\end{tabular}


Table 2. Statistics of NDVI, LSM, LST, and NDISI in 2006 and 2019.

\begin{tabular}{|c|c|c|c|c|c|c|c|c|}
\hline \multirow{2}{*}{} & \multicolumn{4}{|c|}{2006} & \multicolumn{4}{c|}{2019} \\
\cline { 2 - 9 } & NDVI & LSM & LST & NDISI & NDVI & LSM & LST & NDISI \\
\hline MAX & 0.7775 & 1.0000 & 40.0070 & 0.1393 & 0.8231 & 1.0000 & 36.9948 & 0.1857 \\
\hline MIN & -0.7048 & 0.0260 & -14.0536 & -0.6011 & -0.9552 & 0.0190 & -16.3831 & -0.8004 \\
\hline MEAN & 0.2880 & 0.1609 & 19.0286 & -0.2325 & 0.3221 & 0.1373 & 18.3718 & -0.5497 \\
\hline STD & 0.2739 & 0.1422 & 7.8586 & 0.1335 & 0.3155 & 0.0977 & 7.0532 & 0.0962 \\
\hline
\end{tabular}

...where $R S E I_{2006}$ and $R S E I_{2019}$ are the ecological vulnerability index in 2006 and 2019 respectively; $P C_{1}-P C_{3}$ are the first three principal component factors after the principal component transformation of the original spatial variable.

\section{Classification of RSEI and Overall Index of Ecological Vulnerability}

The spatial distribution of RSEI in 2006 and 2019 was obtained by using the Raster Calculator tool in ArcGIS 10.2. According to the interval of 0.2, the RSEI was divided into 5 grades, including lower ecological index (0.0 0.2), low ecological index (0.2 0.4), medium ecological index (0.4 0.6), high ecological index (0.6 0.8), and higher ecological index (0.8 1.0). For the convenience of use, the RSEI was numbered as I, II, III, IV, and V. Meanwhile, in order to study the overall differences of RSEI in different spatial units in different years, this paper uses the Remote-Sensing Ecological Body Index (RSEBI) [40] to estimate it, and its calculation formula is:

$$
R S E B I=\sum_{i=1}^{n} P_{i} \times A_{i} / S
$$

...where $P_{i}$ is the value of ecological vulnerability grade $i$, which is $1-5$. $A_{i}$ is the area of the grade $i ; \mathrm{S}$ is the total area of the study area.

\section{Analysis of Landscape Pattern Change in Different Grades of RSEI}

On the basis of the classification of RSEI, patches of grade I, II, III, IV and V of RSEI were regarded as five landscape types. The landscape indexes are used to study the RSEI of each grade, such as total area (CA), percentage of landscape (PLAND), largest patch index (LPI), number of patches (NP), patch density (PD), landscape division index (DIVISION), splitting index (SPLIT), propotation of like adjacencies (PLADJ), aggregation index (AI), landscape shape index (LSI), and patch cohension index (COHESION).

\section{Results and Discussion}

Analysis on the Temporal and Spatial Variation of Ecological Environment in Kalajun-Kurdening Natural Heritage Site

According to the changes of the indicators of Kalajun-Kurdening heritage site in 14 years, the greenness that has a positive impact on the ecological index shows an upward trend, with the mean value rising from 0.2880 in 2006 to 0.3221 in 2019 , with an increase of $10.58 \%$, which proves that the vegetation coverage in this region shows an increasing trend year by year; The dryness index decreased from -0.2325 in 2006

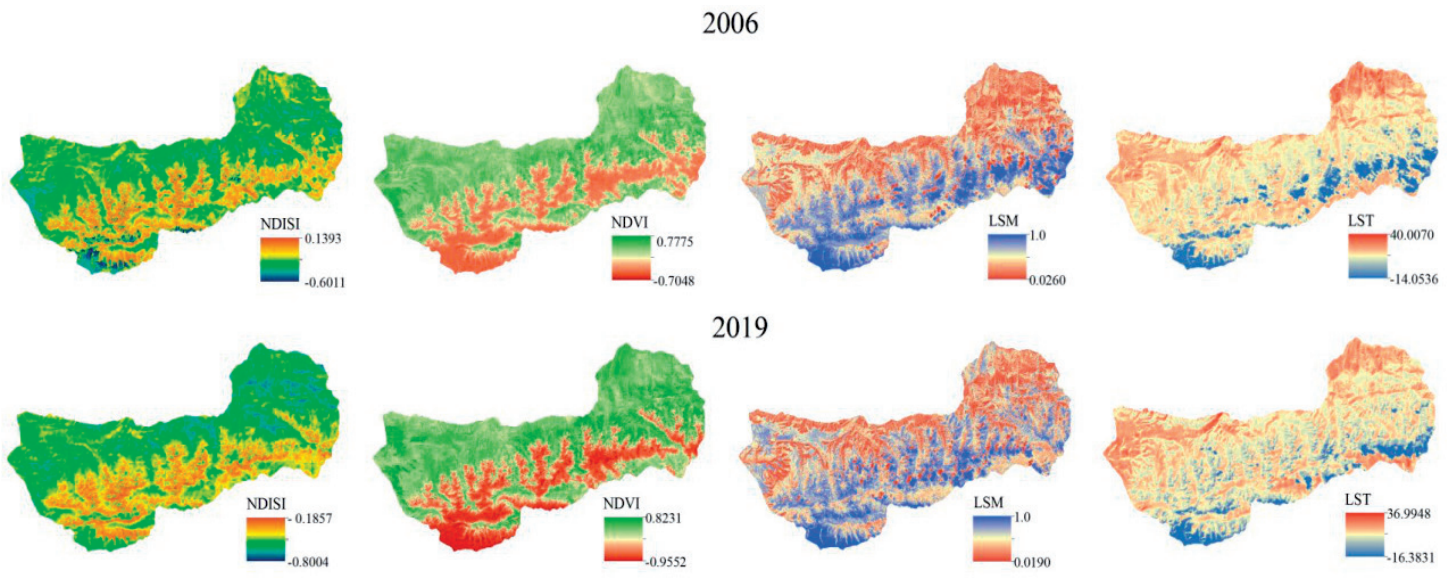

Fig. 2. Spatial distribution of RSEI indicators values in 2006 and 2019. 

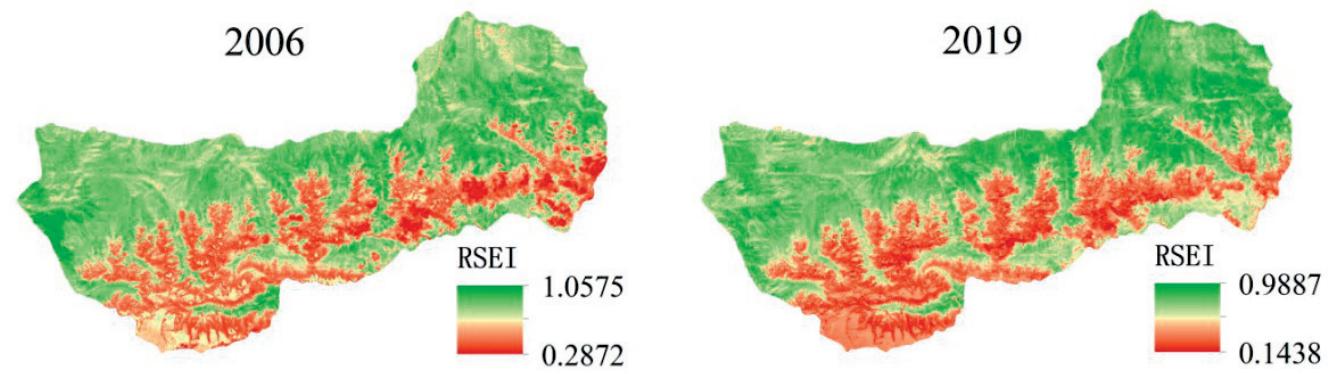

Fig. 3. Distribution of RSEI levels of the study area in 2006 and 2019.
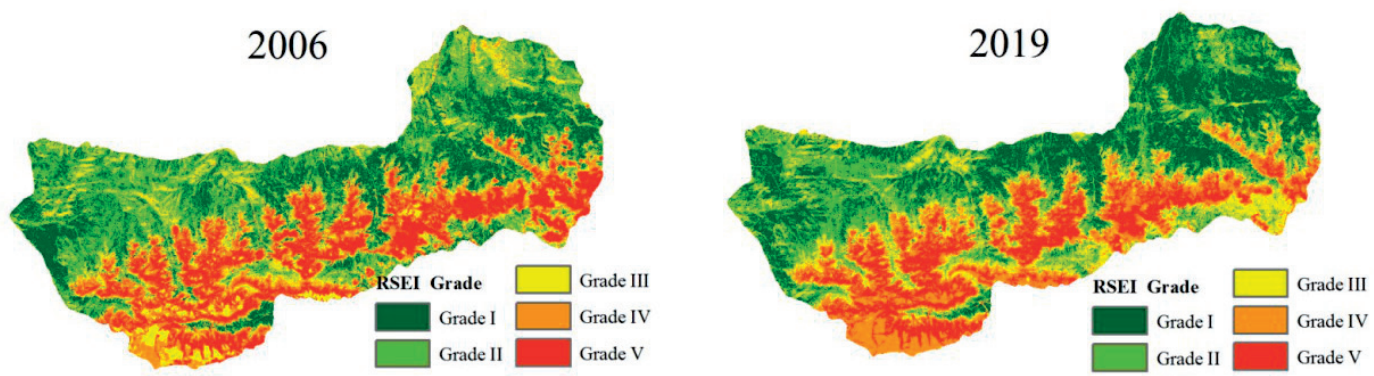

Fig. 4. Spatial distribution of RSEI grades in 2006 and 2019.

to -0.5497 in 2019 , with a decrease of $134.51 \%$, indicating a significant decrease in the degree of surface nudity in the heritage site. The average moisture closely related to vegetation and water resources decreased from 0.1609 in 2006 to 0.1373 in 2019 , with a decrease of $14.66 \%$. The heat indicator, which has a negative effect on the RSEI, shows a downward trend year by year, with its mean dropping from 19.0286 in 2006 to 18.3718 in 2019 , with a decrease ratio of $3.45 \%$. On the whole, the change of greenness and dryness has a stronger positive effect on the ecological environment quality, while the negative effect of heat on the ecological environment quality is reduced. Although moisture is reduced to some extent, the overall effect of positive factors is relatively strong, which promotes the improvement of the RSEI of Kalajun-Kurdening, that is, the ecological environment quality is improved.

From the spatial distribution of RSEI (Fig. 2), NDVI and LSM values are higher in the north of the study area and lower in the south, which are closely related to the distribution of snow, ice and water system. The NDISI value is higher in the south and lower in the north, which is associated with the decrease of snow and ice area in the southwest.

Accordingly, the distribution map of RSEI (Fig. 3) of Kalajun-Kurdening Heritage site is also shown. Compared with 2006, the orange area, which indicates poor ecological environment, gradually spread in 2019, mainly concentrated in the south of the study area. However, the increase of ecological index in the northern region, especially in the northeast region, indicates that the ecological environment has been improved to a great extent.

For more in-depth analysis of RSEI space changes of Kalajun-Kurdening, the RSEI was divided into 5 grades according to the interval of 0.2 , including Grade I $(0.0 \leq \mathrm{RSEI} \leq 0.2)$, Grade II $(0.2 \leq \mathrm{RSEI} \leq 0.4)$, Grade III $(0.4 \leq \mathrm{RSEI} \leq 0.6)$, Grade IV $(0.6 \leq \mathrm{RSEI} \leq 0.8)$, and Grade $\mathrm{V}(0.8 \leq \mathrm{RSEI} \leq 1.0)$, and the specific calculation results as shown in Fig. 4 and Table 3.

From Fig. 4, in 2006, the northern part of the study area was covered by a large area with a low RSEI, while the area with a high RSEI was scattered; In the southern direction, RSEI is rising gradually, but the areas with medium and high ecological index are only scattered. In 2019, a large area of the northern part of the study area, especially the northeast region, experienced a decrease of RSEI, while the southern part of the study area, especially the southeast and southwest regions, experienced an increase in low-value areas and a significant increase in high-value areas.

Table 3 and Fig. 5 show the area and proportion of each grade of RSEI in the study area and its change curve. In 2006, the area with Grade I of RSEI was $429.12 \mathrm{~km}^{2}$, accounting for $21.12 \%$; By 2019 , the area of Grade I is $540.33 \mathrm{~km}^{2}$, accounting for $26.70 \%$, with an increase of $111.21 \mathrm{~km}^{2}$. Although the range of change is not large, it also indicates that the area with low RSEI is increasing. The area with Grade II occupies a large proportion in the whole study area, with the area of $641.21 \mathrm{~km}^{2}$, accounting for $31.56 \%$ of the total area, and an area of $570.99 \mathrm{~km}^{2}$, accounting for $28.06 \%$, 
Table 3. Percentage of areas of RSEI grades of the study area in 2006 and 2019.

\begin{tabular}{|c|c|c|c|c|}
\hline \multirow{2}{*}{ Grade of RSEI } & \multicolumn{2}{|c|}{2006} & \multicolumn{2}{c|}{2019} \\
\cline { 2 - 5 } & Area/km ${ }^{2}$ & Percent $/ \%$ & Area $/ \mathrm{km}^{2}$ & Percent $/ \%$ \\
\hline I & 429.12 & 21.12 & 540.33 & 26.70 \\
\hline II & 641.21 & 31.56 & 570.99 & 28.06 \\
\hline III & 332.37 & 16.34 & 327.88 & 14.62 \\
\hline IV & 263.18 & 12.98 & 295.07 & 14.52 \\
\hline V & 365.76 & 18.00 & 2031.64 & 100 \\
\hline Total & 2031.64 & 100 & & 10 \\
\hline
\end{tabular}

reducing by $70.22 \mathrm{~km}^{2}$. The area of Grade III decreased from $332.37 \mathrm{~km}^{2}$ in 2006 to $297.37 \mathrm{~km}^{2}$ in 2019 , and the proportion decreased from $16.34 \%$ to $14.62 \%$, which was basically stable. The area of Grade IV increased from $263.18 \mathrm{~km}^{2}$ in 2006 to $327.88 \mathrm{~km}^{2}$ in 2019 , and the corresponding proportion increased from $12.98 \%$ to $16.10 \%$, with an increase of $64.70 \mathrm{~km}^{2}$. The area of Grade V decreased by $70.69 \mathrm{~km}^{2}$ from $365.76 \mathrm{~km}^{2}$ in 2006 to $295.07 \mathrm{~km}^{2}$, and the corresponding proportion increased from $18 \%$ to $14.52 \%$.

The statistical value of RSEI of various grades in the research area shows that the ecological environment has changed with ups and downs over the past 14 years, but it is basically balanced on the whole. In terms of proportion, the ecological index distribution of the whole research area is relatively balanced, with Grade I and Grade II areas accounting for $54.76 \%$ of the total area in 2016. Grade III, IV and V areas account for $45.22 \%$ of the total area, so the overall level of ecological environment still needs to be improved.

\section{Dynamic Monitoring of Eco-Environment Quality} in Kalajun-Kurdening Natural Heritage Site

In order to further analyze the variation characteristics of the RSEI of Kalajun-Kurdening, the RSEI of the two time phases was compared, and the spatial variation chart of RSEI was obtained by

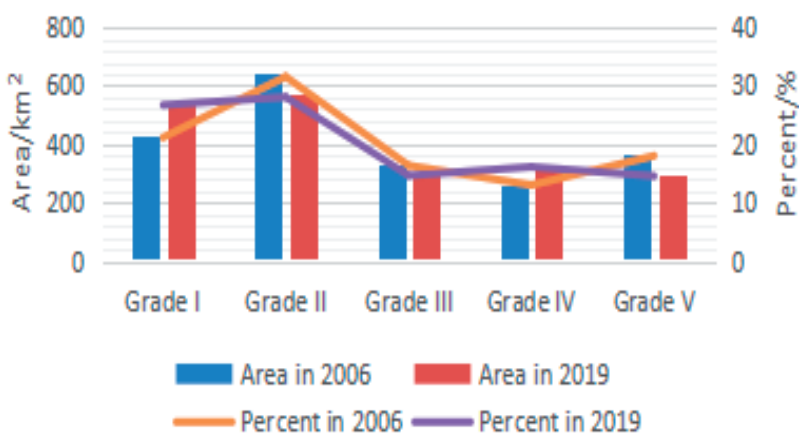

Fig. 5. Statistical chart of ecological grades and area ratios in 2006 and 2019 classifying the RSEI from three levels: descending, unchanged and ascending (Fig. 6). The results show that the increasing area of RSEI is mostly located in the southeast and south edge of the study area. Most of the RSEI invariant areas were scattered, and there were more in the southeastern region. The decline of RSEI is mainly distributed in the northwest of the study area, especially in the snow and ice area.

According to statistics on the specific changes of each grade (Table 4), from 2006 to 2019, the regional RSEI of $1104.23 \mathrm{~km}^{2}$ remained unchanged, accounting for $54.32 \%$ of the total area. The area with a descending RSEI is $547.23 \mathrm{~km}^{2}$, accounting for $26.92 \%$ of the total area, and $84.52 \%$ of the area has a descending ecological index of one level. The area with the rising RSEI is $381.31 \mathrm{~km}^{2}$, accounting for $18.75 \%$ of the total area, of which $90.56 \%$ has the rising ecological index by one level. Therefore, the changes in the RSEI of the research area are mainly concentrated within a range of one level, indicating that the ecosystem of the whole Kalajun-Kurdening heritage site has been relatively stable in the past 14 years without large-scale deterioration of the ecological environment, and the overall trend of development is good.

Analysis of landscape pattern change in different grades of RSEI of Kalajun-Kurdening natural heritage site.

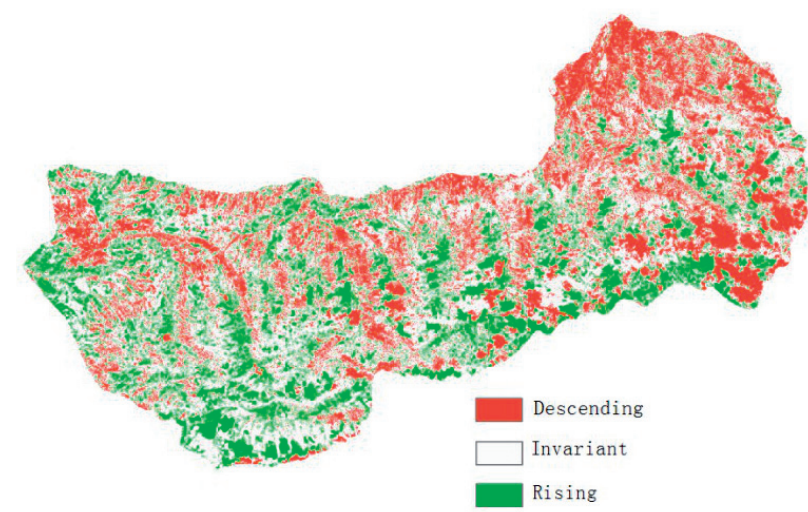

Fig. 6. RSEI hierarchical spatial distribution of the study area. 
Table 4. Change of RSEI Grade in the study area.

\begin{tabular}{|c|c|c|c|c|}
\hline Levels of RSEI & Range & Area of each level $/ \mathrm{km}^{2}$ & Proportion/\% & Class Area $/ \mathrm{km}^{2}$ \\
\hline \multirow{4}{*}{ Descending } & -4 & 3.01 & 0.55 & \multirow{4}{*}{547.23} \\
\hline & -3 & 16.26 & 2.97 & \\
\hline & -2 & 65.46 & 11.96 & \\
\hline & -1 & 462.50 & 84.52 & \\
\hline Invariant & 0 & 1104.23 & - & 1104.23 \\
\hline \multirow{4}{*}{ Rising } & 1 & 345.34 & 90.56 & \multirow{4}{*}{381.31} \\
\hline & 2 & 28.57 & 7.49 & \\
\hline & 3 & 6.31 & 1.66 & \\
\hline & 4 & 1.09 & 0.29 & \\
\hline
\end{tabular}

Table 5. Change in landscape patch characteristic values from 2006 to 2019 of the study area.

\begin{tabular}{|c|c|c|c|c|c|c|c|c|c|c|}
\hline \multirow{2}{*}{ Type } & \multicolumn{2}{|c|}{ CA } & \multicolumn{2}{|c|}{ PLAND } & \multicolumn{2}{|c|}{ NP } & \multicolumn{2}{|c|}{ PD } & \multicolumn{2}{|c|}{ LPI } \\
\hline & 2006 & 2019 & 2006 & 2019 & 2006 & 2019 & 2006 & 2019 & 2006 & 2019 \\
\hline I & 429.13 & 540.33 & 21.10 & 26.57 & 15284 & 8344 & 7.51 & 4.10 & 1.79 & 11.03 \\
\hline II & 641.31 & 570.99 & 31.54 & 28.08 & 1297 & 11085 & 6.38 & 5.45 & 13.82 & 12.08 \\
\hline III & 332.47 & 297.37 & 16.35 & 14.62 & 18913 & 12333 & 9.30 & 6.06 & 0.53 & 1.42 \\
\hline IV & 263.28 & 327.88 & 12.95 & 16.12 & 10976 & 7955 & 5.31 & 3.91 & 0.94 & 2.01 \\
\hline V & 366.67 & 296.29 & 18.03 & 14.57 & 3573 & 3795 & 1.75 & 1.96 & 7.17 & 6.06 \\
\hline Total & 2032.86 & 2032.86 & - & - & 61719 & 43512 & - & - & - & - \\
\hline \multirow{2}{*}{ Type } & \multicolumn{2}{|c|}{ LSI } & \multicolumn{2}{|c|}{ PLADJ } & \multicolumn{2}{|c|}{ COHESION } & \multicolumn{2}{|c|}{ DIVISION } & \multicolumn{2}{|c|}{ AI } \\
\hline & 2006 & 2019 & 2006 & 2019 & 2006 & 2019 & 2006 & 2019 & 2006 & 2019 \\
\hline I & 149.38 & 107.11 & 78.35 & 86.17 & 98.32 & 99.50 & 0.99 & 0.98 & 78.46 & 86.28 \\
\hline II & 209.56 & 179.73 & 75.16 & 77.42 & 99.66 & 99.59 & 0.97 & 0.98 & 75.25 & 77.51 \\
\hline III & 204.22 & 170.67 & 66.38 & 70.29 & 95.30 & 97.42 & 0.99 & 0.99 & 66.49 & 70.42 \\
\hline IV & 169.51 & 133.37 & 68.65 & 77.88 & 97.21 & 98.47 & 0.99 & 0.99 & 68.77 & 78.01 \\
\hline V & 72.06 & 77.02 & 88.70 & 86.57 & 99.62 & 99.49 & 0.99 & 0.99 & 88.84 & 86.72 \\
\hline
\end{tabular}

RSEI patch I, II, III, IV and V were regarded as five landscape types, and the landscape index is used to study the RSEI of each grade. Fragstats 4.2 was used to calculate each index, and the specific calculation results are shown in Table 5.

The number of patches (NP) and patch density index (PD) are indicators reflecting landscape fragmentation [41]. As can be seen from Table 5, the total area (CA) of the study area was $2032.86 \mathrm{~km}^{2}$, and the number of patches was 61,719 in 2006 and 43,512 in 2019. The number of patches in the Grade I region decreased from 15,284 to 8,344 , which was the highest reduction in the number of patches in the Grade I region; It indicates that the landscape fragmentation in Grade I region has the largest reduction range, that is, the area with the lowest ecological index has a reduction in patch number and a reduction in landscape fragmentation. The number of patches in Grade II and Grade V regions increased from 1297 and 3573 to 11085 and 3795 respectively, which are the two regions with increased number of patches among the five regions; the patch increase in Grade $\mathrm{V}$ region, that is, the area with high RSEI, was less, indicating a small degree of landscape fragmentation. The number of patches in both Grade III and Grade IV areas also decreased to varying degrees. The patch density also decreased in all grades areas. In general, the landscape fragmentation of the study area from 2006 to 2019 is relatively small, and there is no large-scale deterioration of the ecological environment.

In 2006 and 2019, the difference of PLAND index of each grade area was not significant. The total proportion of regions of Grade I and Grade II were 
$52.64 \%$ and $54.65 \%$ respectively, and the proportion of regions of Grade III-V were $47.33 \%$ and $45.31 \%$ respectively in the two years, which basically kept stable, indicating that the overall ecological environment of Kalajun-Kurdening kept a good state. Landscape shape index (LSI) is an index to characterize the complexity of landscape structure [42]. The LSI of the Grade I-IV region all decreased to different degrees, while the LSI of the Grade V region increased slightly from 72.06 to 77.02, indicating that the structural complexity of most areas in Kalajun-Kurdening was reduced, and the landscape patches were regularized, artificial and centralized. The DIVISION index was basically maintained at $0.98-0.99$, indicating that the overall RSEI patch shape complexity of the study area was not high. PLADJ of Grade I-IV increased from 2006 to 2019, while that of Grade V decreased by 2.13 , which reflects the strong connectivity of certain patches in the RSEI landscape on the whole. COHESION was used to characterize the natural connectivity of landscape patches [43]. The COHESION of RSEI of the study area was close to 100 , indicating a good patch binding. The landscape aggregation index (AI) represents the ratio of the number of adjacent common edges of the grid to the number of maximum possible common edges of a landscape element [44]. The AI showed an increase in the overall analysis of the study area, indicating that there was no increase in small patches. To sum up, the performance of each index in each grade area is consistent.

Through the analysis of RSEI and landscape pattern index, it is concluded that Kalajun-Kurdening natural heritage site maintains good ecological environment and typical biodiversity and landscape aesthetic value. This is mainly due to the coupling of natural environment changes and human activities:

(1) From the perspective of natural factors, the Kalajun-Kurdening natural heritage site is located in the hinterland of Eurasia and has a temperate continental semi-humid climate with long winters and short summers. There is large daily temperature difference, sufficient sunlight and moderate thermal energy. The annual average temperature is $5-7^{\circ} \mathrm{C}$, and the annual average relative humidity is $70 \%$ [45]. With such favorable climatic conditions, from 2006 to 2019, the aggregation index of landscape was improved, and the overall landscape structure is relatively stable. The overall landscape health status and biodiversity of the study area are well maintained, and it has a complete natural geographical landscape aesthetic value.

(2) From the perspective of human activities, West Tianshan National Nature Reserve was established with the approval of the State Council in 2000. Kalajun Original Ecological Prairie Scenic Spot was established in 2007, which is a public institution under the jurisdiction of the Tourism Bureau of Turks County, covering an area of 100,000 mu; In 2010, KaLajun Scenic Spot was established; In 2013, Kalajun-Kurdening was included in the World Natural Heritage List as part of Xinjiang Tianshan World Natural Heritage Site [46]. In 2015, Karajun actively promoted the construction of national $5 \mathrm{~A}$ scenic spot was actively promoted and the construction of tourism infrastructure was constantly improved in Kalajun, and it was promoted to national 5A scenic spot in November 2016 [47]. From 2006 to 2019, the landscape tends to be stable, indicating that the establishment of the nature reserve and the natural heritage site in the study area has played a role in protecting the integrity of the landscape. Furthermore, in 2016, the Turks County government proposed the "herdsmen settlement" project through the investigation of Kalajun, and let herdsmen move out of the original earth houses and settle in a centralized location [48]. For example, the higher greenness and humidity in the northern part of the study area were mainly due to vegetation restoration measures. These reflect the work of heritage protection, government policies and the production and life style of local residents, and have made great contributions to the maintenance of the outstanding universal value of natural heritage sites and the aesthetic value of the landscape.

On research methods, based on the comparative analysis of the spatial distribution of two phases of RSEI in the study area, this paper revealed the status quo and spatial distribution characteristics of the ecological environment in the study area, discussed the spatial variation rules of the ecological environment, and tried to analyze the landscape pattern characteristics from the perspective of RSEI grade, so as to further refine the study on the change of the ecological environment, and to some extent, make up the deficiency of the existing studies on the analysis of landscape pattern. However, in terms of time sample selection, only 2006 and 2019 data were selected, which failed to characterize some potential special time nodes and time series characteristics of the ecological environment of Kalajun-Kurdening World Natural Heritage site. These deficiencies need to be further improved in the future research.

\section{Conclusions}

Based on Landsat satellite remote sensing data, the four indicators of greenness, moisture, dryness and heat were coupled into RSEI by SPCA method, and the ecological classification was combined with landscape pattern analysis to study the objective and quantitative spatio-temporal changes and dynamic monitoring of the ecological environment of Karajun-Kurdening World Natural Heritage site in 14 years, analyzing the present situation and the spatial distribution characteristics of the RSEI in Kalajun-Kurdening from 2006 to 2019. The result of the research shows that:

(1) From the perspective of spatial and temporal distribution, the overall ecological environment quality of the Kalajun-Kurdening World Natural Heritage 
site showed an upward trend from 2006 to 2019. The greenness indicator that has a positive impact on the RSEI shows an increasing trend, with an increase of $10.58 \%$, which proves that the vegetation coverage in Kalajun-Kurdening shows an increasing trend year by year. The dryness indicator decreased by $134.51 \%$, indicating that the degree of surface exposure in the basin was greatly reduced. The mean moisture, which is closely related to vegetation and water resources, decreases by $14.66 \%$. The heat indicator, which has a negative effect on the RSEI, showed a downward trend year by year, with a decrease ratio of $3.45 \%$. On the whole, the change of greenness and dryness has a stronger positive effect on the ecological environment quality, while the negative effect of heat on the ecological environment quality is reduced. Although moisture is reduced to some extent, the overall effect of positive factors is relatively strong, which promotes the improvement of the RSEI of the research area, that is, the ecological environment quality of KalajunKurdening is improved.

(2) According to the dynamic monitoring, the ecological environment of Kalajun-Kuerdening World Natural Heritage site was maintained in good condition from 2006 to 2019, and the regional RSEI of $1104.23 \mathrm{~km}^{2}$ remained unchanged, accounting for $54.32 \%$ of the total area. The area with a descending RSEI is $547.23 \mathrm{~km}^{2}$, accounting for $26.92 \%$ of the total area, $84.52 \%$ of which had a drop of one level. The area with the rising RSEI is $381.31 \mathrm{~km}^{2}$, accounting for $18.75 \%$ of the total area, $90.56 \%$ of which has a rising by one level. Therefore, the changes of RSEI of Kalajun-Kurdening are mainly concentrated within a range of one level, indicating that the ecosystem of the whole area has been relatively stable in the past 14 years without large-scale deterioration of the ecological environment, and the overall trend of development is good.

(3) From the perspective of landscape pattern analysis, landscape indexes of the study area such as NP, PD, and LSI generally show a downward trend, indicating that the landscape fragmentation is small, the structural complexity is reduced, and the landscape patches are regularized, artificial, and centralized; PLADJ and AI showed an overall trend of increase, indicating that the connectivity between patches was good, that is, different types of RSEI had obvious agglomeration; COHESION was close to 100 , indicating that the cohesion between patches was relatively good; PLAND and DIVISION kept basically stable. The indexes of each grade area are consistent, which indicates that the ecological environment of the study area is in good condition.

Overall, the ecological environment quality of the Kalajun-Kurdening world natural heritage site showed an upward trend from 2006 to 2019 without large-scale deterioration of, maintaining in good condition.

\section{Conflict of Interest}

The authors declare no conflict of interest.

\section{References}

1. http://whc.unesco.org/en/conventiontext/

2. SHI H., YANG Z., HAN F., SHI T., LUAN F. Characteristics of temporal-spatial differences in landscape ecological security and the driving mechanism in Tianchi scenic zone of Xinjiang. Progress in Geography. 32, 475, 2013.

3. LIU Q., YANG Z., HAN F., SHI H., WANG Z., CHEN $X$. Ecological Environment Assessment in World Natural Heritage Site Based on Remote-Sensing Data. A Case Study from the Bayinbuluke. Sustainability. 11, 2019.

4. ALLAN J.R., VENTER O., MAXWELL S., BERTZKY B., JONES K., SHI Y., WATSON J.E.M. Recent increases in human pressure and forest loss threaten many Natural World Heritage Sites. Biological Conservation. 206, 47, 2017.

5. SHI H., YANG Z., HAN F., LUAN F., SHI T. Assessment and analysis of eco-environment vulnerability in Tomur region of natural heritage site. Arid Land Geography. 36, 318, 2013.

6. WANG Z., YANG Z., SHI H., HAN F., LIU Q., QI J., LU Y. Ecosystem Health Assessment of World Natural Heritage Sites Based on Remote Sensing and Field Sampling Verification: Bayanbulak as Case Study. Sustainability. 12, 2020.

7. HE L., SHEN J., ZHANG Y. Ecological vulnerability assessment for ecological conservation and environmental management. Journal of Environmental Management. 206, 1115, 2018.

8. HE Y., YUAN Y., WANG T., ZHANG H., CHEN Y. Integrated assessment of marine ecological vulnerability in the Yangtze River Estuary using GIS. Acta Ecologica Sinica. 39, 3918, 2019.

9. NESHEIM I., BARKVED L. The Suitability of the Ecosystem Services Framework for Guiding Benefit Assessments in Human-Modified Landscapes Exemplified by Regulated Watersheds - Implications for a Sustainable Approach. Sustainability. 11, 2019.

10. HAN X., WANG P., WANG J., QIAO M., ZHAO X. Evaluation of human-environment system vulnerability for sustainable development in the Liupan mountainous region of Ningxia, China. Environmental Development. 34, 2020.

11. KRISHNAN S.V., FIROZ M.C. Regional urban environmental quality assessment and spatial analysis. Journal of Urban Management. 9, 191, 2020.

12. LIU H., SHI X. Spatio-temporal Evolution and Zoning of Ecological Vulnerability of Jingle County. Journal of Ecology and Rural Environment. 36, 34, 2020.

13. ZHOU M., CAI Y., ZHANG R., LIU J., SONG X. The tempo-spatial pattern of regional ecological vulnerability before and after the establishment of National Nature Reserve in Helan Mountain of Ningxia. Ecologic Science. 38, 78, 2019.

14. HAN X., LIU C., HU J., WANG X., LUO L., ZHAO Y., LI L., JI X., YAN H., WANG Y. Dynamic evolution of landscape pattern and ecological health assessment of Tianshan Natural Heritage Site in Xinjiang. Arid Land Geography. 42, 195, 2019. 
15. DING Q., WANG L., FU M., HUANG N. An integrated system for rapid assessment of ecological quality based on remote sensing data. Environmental Science and Pollution Research. 2020.

16. PINO J., MARULL J. Ecological networks: Are they enough for connectivity conservation? A case study in the Barcelona Metropolitan Region (NE Spain). Land Use Policy. 29, 684, 2012.

17. BLASCHKE T. Object based image analysis for remote sensing. ISPRS Journal of Photogrammetry and Remote Sensing. 65, 2, 2010.

18. JIANG L., HUANG X., WANG F., LIU Y., AN P. Method for evaluating ecological vulnerability under climate change based on remote sensing: A case study. Ecological Indicators. 85, 479, 2018.

19. BADRELDIN N., FRANKL A., GOOSSENS R. Assessing the spatiotemporal dynamics of vegetation cover as an indicator of desertification in Egypt using multi-temporal MODIS satellite images. Arabian Journal of Geosciences. 7, 4461, 2014.

20. FRANKE J., KEUCK V., SIEGERT F. Assessment of grassland use intensity by remote sensing to support conservation schemes. Journal for Nature Conservation. 20, 125, 2012.

21. ZHANG J.X., LI H.Y., CAO E.J., GONG J. Assessment of ecological vulnerability in multi-scale and its spatial correlation: A case study of Bailongjiang Watershed in Gansu Province, China. Ying yong sheng tai xue bao = The journal of applied ecology. 29, 2897, 2018.

22. XU H. A remote sensing index for assessment of regional ecological changes. China Environmental Science. 33, 889, 2013.

23. LI H., XU F., LI Q. Remote sensing monitoring of land damage and restoration in rare earth mining areas in 6 counties in southern Jiangxi based on multisource sequential images. Journal of Environmental Management. 267, 2020.

24. XU H., WANG Y., GUAN H., SHI T., HU X. Detecting Ecological Changes with a Remote Sensing Based Ecological Index (RSEI) Produced Time Series and Change Vector Analysis. Remote Sensing. 11, 2019.

25. HUYLENBROECK L., LASLIER M., DUFOUR S., GEORGES B., LEJEUNE P., MICHEZ A. Using remote sensing to characterize riparian vegetation: A review of available tools and perspectives for managers. Journal of Environmental Management. 267, 2020.

26. ALTAMIRANO A., GONZALEZ-SUHR C., MARIEN C., CATALAN G., MIRANDA A., PRADO M., TITS L., VIELI L., MELI P. Landscape Disturbance Gradients: The Importance of the Type of Scene When Evaluating Landscape Preferences and Perceptions. Land. 9, 2020.

27. XU J., ZHAO H., YIN P., WU L., LI G. Landscape ecological quality assessment and its dynamic change in coal mining area: a case study of Peixian. Environmental Earth Sciences. 78, 2019.

28. XU H., HU X., GUAN H., ZHANG B., WANG M., CHEN S., CHEN M. A Remote Sensing Based Method to Detect Soil Erosion in Forests. Remote Sensing. 11, 2019

29. DING D., JIANG Y., WU Y., SHI T. Landscape character assessment of water-land ecotone in an island area for landscape environment promotion. Journal of Cleaner Production. 259, 2020

30. ZHU Z., BI J., PAN Y., GANGULY S., ANAV A., XU L., SAMANTA A., PIAO S., NEMANI R. R., MYNENI R. B. Global Data Sets of Vegetation Leaf Area Index (LAI) $3 \mathrm{~g}$ and Fraction of Photosynthetically Active Radiation
(FPAR)3g Derived from Global Inventory Modeling and Mapping Studies (GIMMS) Normalized Difference Vegetation Index (NDVI3g) for the Period 1981 to 2011. Remote Sensing. 5, 927, 2013.

31. SHI T., XU H. Derivation of Tasseled Cap Transformation Coefficients for Sentinel-2 MSI At-Sensor Reflectance Data. Ieee Journal of Selected Topics in Applied Earth Observations and Remote Sensing. 12, 4038, 2019.

32. SHAN W., JIN X., REN J., WANG Y., XU Z., FAN Y., GU Z., HONG C., LIN J., ZHOU Y. Ecological environment quality assessment based on remote sensing data for land consolidation. Journal of Cleaner Production. 239, 2019.

33. WU T., SANG S., WANG S., YANG Y., LI M. Remote sensing assessment and spatiotemporal variations analysis of ecological carrying capacity in the Aral Sea Basin. Science of the Total Environment. 735, 2020.

34. NAGENDRA H., LUCAS R., HONRADO J. P., JONGMAN R. H. G., TARANTINO C., ADAMO M., MAIROTA P. Remote sensing for conservation monitoring: Assessing protected areas, habitat extent, habitat condition, species diversity, and threats. Ecological Indicators. 33, 45, 2013

35. XU X. ,Environmental Quality Assessment of Tibet Based on 3S, in Progress in Environmental Protection and Processing of Resource, Pts 1-4, edited by X. Tang, W. Zhong, D. Zhuang, C. Li,Y. Liu, 692, 2013.

36. KUBISSA W., JASKULSKI R., CHEN J., PUI-LAM N. G., GODLEWSKA W., REITERMAN P. Evaluation of ecological concrete using multi-criteria ecological index and performance index approach. Architecture Civil Engineering Environment. 12, 97, 2019.

37. LIU G., WANG J., LI S., LI J., DUAN P. Dynamic Evaluation of Ecological Vulnerability in a Lake Watershed Based on RS and GIS Technology. Polish Journal of Environmental Studies. 28, 1785, 2019

38. YANG H., ZHAI G., ZHANG Y. Ecological vulnerability assessment and spatial pattern optimization of resourcebased cities: A case study of Huaibei City, China. Human and Ecological Risk Assessment. 2020.

39. GUO Z., WEI W., PANG S., LI Z., ZHOU J., XIE B. Spatio-Temporal evolution and motivation analysis of ecological vulnerability in Arid Inland River Basin based on SPCA and remote sensing index: A case study on the Shiyang River Basin. Acta Ecologica Sinica. 39, 2558, 2019.

40. LIU Q., SHI T. Spatiotemporal Differentiation and the Factors of Ecological Vulnerability in the Toutun River Basin Based on Remote Sensing Data. Sustainability. 11, 2019.

41. PASCUAL-HORTAL L., SAURA S. Comparison and development of new graph-based landscape connectivity indices: towards the priorization of habitat patches and corridors for conservation. Landscape Ecology. 21, 959, 2006.

42. XU X., CAI H., QIAO Z., WANG L., JIN C., GE Y., WANG L., XU F. Impacts of park landscape structure on thermal environment using QuickBird and Landsat images. Chinese Geographical Science. 27, 818, 2017.

43. HOU L., WU F., XIE X. The spatial characteristics and relationships between landscape pattern and ecosystem service value along an urban-rural gradient in $\mathrm{Xi}^{6}$ an city, China. Ecological Indicators. 108, 2020.

44. AZHDARI A., SOLTANI A., ALIDADI M. Urban morphology and landscape structure effect on land surface temperature: Evidence from Shiraz, a semi-arid city. Sustainable Cities and Society. 41, 853, 2018. 
45. LIU H., YANG Z., WANG C., HAN F., WANG Z. Camping Suitability of World Natural Heritage Based on GIS: A Case Study in Kurderning,A world Heritage in the Tianshan Mountains,Xinjiang. Arid Zone Research. 33, 843, 2016.

46. WU K., XU T., XU H., ZHANG C., XU W., YANG W. Comparison of different grazing systems on subalpine meadow of tianshan Natural Heritage. Pratacultural Science. 32, 2139, 2015.
47. WANG Z., YANG Z., CAO K., AN Q., LIU Q., WANG C. Community Cognition on the Protection of World Natural Heritage and Its Affecting Factors: A Case Study in the Kalajun World Natural Heritage Site. Arid Zone Research. 33, 1311, 2016.

48. HU J., YAO J. Dependency between herdsmen's diversified livelihoods and grassland ecosystem services: Taking the Kalajun World Natural Heritage Site as an example. Pratacultural Science. 37, 800, 2020. 